\title{
Influence of the temporal resolution of the water consumption profile on photovoltaic water pumping systems modelling and sizing
}

\author{
Simon Meunier, Loic Queval*, Arouna Darga \\ Philippe Dessante, Claude Marchand \\ GeePs | Group of electrical engineering - Paris \\ UMR CNRS 8507, CentraleSupélec, Univ. Paris-Sud, \\ Université Paris-Saclay, Sorbonne Université \\ Gif-sur-Yvette, France \\ *Corresponding author: loic.queval@centralesupelec.fr \\ Judith Cherni \\ Centre for Environmental Policy \\ Imperial College London \\ London, UK
}

\author{
Matthias Heinrich \\ DargaTech SARL \\ Ouagadougou, Burkina Faso
}

\author{
Lionel Vido \\ SATIE | Systèmes et Applications des Technologies de \\ l'Information et de l'Energie \\ Univ. de Cergy-Pontoise \\ Cergy-Pontoise, France
}

\author{
Bernard Multon \\ SATIE \\ ENS Rennes, Université de Rennes, CNRS \\ Bruz, France
}

\begin{abstract}
Photovoltaic water pumping could significantly improve water access, particularly in off-grid rural villages of Sub-Saharan Africa. Earlier, we have developed and validated a numerical model of a photovoltaic water pumping system (PVWPS). Such model allows to include the water consumption profile as an input. The current study assesses the influence of the temporal resolution of the water consumption profile on the model accuracy and on PVWPS optimal sizing. This helps to select the adapted temporal resolution for data acquisition, modelling and optimization in order to keep data storage and computational time low without significantly changing the accuracy of the model and the sizing obtained from the optimization. Our study shows that the temporal resolution has a strong impact on modelling and optimal system sizing.
\end{abstract}

Keywords - Photovoltaic; Pumping; Temporal resolution; Water consumption

\section{INTRODUCTION}

In Sub-Saharan Africa, more than 300 million people use unimproved water sources and most of them live in rural areas [1]. This unimproved water access is associated with significant ill-health and time losses [2][3]. Amongst the different alternatives for improving water access, photovoltaic (PV) pumping constitutes a suitable solution especially for offgrid rural areas. Indeed, photovoltaic water pumping systems (PVWPS) are economically competitive in rural areas [4],

This work is supported by a public grant overseen by the French National research Agency (ANR) as part of the « Investissement d'Avenir » program, through the "IDI 2015" project funded by the IDEX Paris-Saclay, ANR-11IDEX0003-02. reliable [4] [5] and maintenance needs are low [6] [7].

The modelling, design, control and application of PVWPS have been extensively discussed in the literature. Components which are well adapted to photovoltaic water pumping have been designed, such as the motor drive using PV transistors detailed in [8]. Several control strategies of PVWPS have been investigated such as the parallel distributed compensation control [9] and the fuzzy logic control [10]. Krim et al. also investigated the use of the Field-Programmable Gate Array (FPGA) to control the converters of PVWPS [11], Koreboina et al. studied the switched reluctance motor Pulse Width Modulation (PWM) control for PV water pumping [12] and Akeyo et al. proposed a strategy to control an array of pumps [13]. As to cases of applications, Yahyaoui et al. studied the use of PVWPS for tomato irrigation [14] and Sodiki investigated the application of PVWPS for agriculture and domestic water access in Nigeria [15].

Most of the PVWPS models considered in previous studies compute the pumped water volume using climatic data (irradiance, temperature) as only input and then compare this pumped volume to the water volume required. However, to our best knowledge, none of available data validated models has taken the water consumption profile as an input. Such overlook represents a problem for PVWPS which include a tank and a controller that stops and restarts the pump depending on the water level in the tank. Indeed, for these systems the water 
consumption profile has an impact on the water level in the tank and therefore on the evolution of the pumped flow rate. We have developed and validated a PVWPS model which takes into account for the first time, to our knowledge, water consumption as an input. This model allows to simulate the operation of PVWPS with the architecture mentioned above, which are very common in rural areas, and it permits to optimize the sizing of these systems.

As water consumption is included as model input, it is important to determine the temporal resolution required for this input. Indeed, this resolution may influence the model accuracy and therefore the results of sizing studies that are based on this model. Currently, the greatest majority of studies on communal PV water pumping in rural areas consider the total volume of water consumed per day. In addition, no study regarding the influence of the water consumption profile temporal resolution on PVWPS model accuracy has been encountered. However, similar studies have been found regarding the influence of the electrical consumption profile temporal resolution on the accuracy of PV-battery systems models and on the optimal sizing of these systems [16] [17]. These latter systems are close to PVWPS with tank as the battery plays the role of the tank and the load profile can be assimilated to the water consumption profile. For PV-battery systems, Notton et al. advice to avoid time steps larger than 1 hour for the electrical consumption profile [16]. Hoevenaars and Crawford showed that using simulation time steps of 1 hour instead of 1 minute had a small effect on the PV-battery systems optimal sizing [17]. However, the simultaneous variation of the temporal resolution of the irradiance and of the electrical consumption is performed in this study, which prevents from isolating the effect of the electrical consumption profile temporal resolution.

In this article, we study the impact of the temporal resolution of the water consumption profile on the PVWPS model accuracy and on the optimal sizing. This provides information for selecting time steps for data acquisition, modelling and optimization that save data storage capacity and computational time without greatly impacting the results.

The PVWPS model and the test system to which it is applied are described in section 2; the different temporal resolutions of the water consumption profile are presented in section 3; the effects of the change of the temporal resolution on PVWPS modelling and sizing are detailed in sections 4 and 5 respectively.

\section{PhOtovoltaic WATER PUMPING SYSTEM MODEL}

The PVWPS model developed is presented in detail in [18]. This model applies to systems with the architecture presented in Fig. 1. In this architecture, the controller regulates the energy provided by the PV modules to the motor-pump according to two set points of the water level in the tank, which is obtained by a float switch. Pipe assemblies PA1 and PA2 are two piping systems that link the motor-pump to the tank and the tank to the fountain respectively. The inhabitants collect water at the fountain.

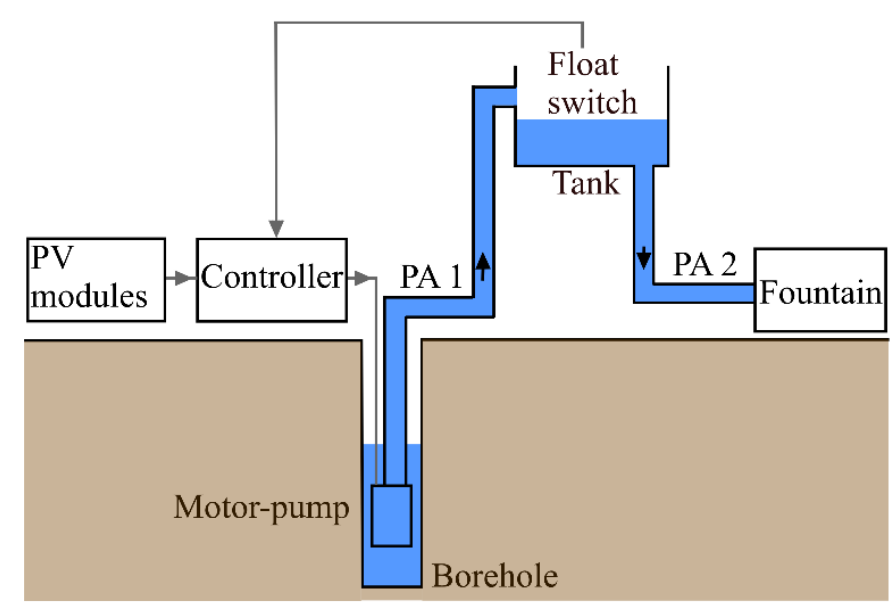

Fig. 1 PVWPS architecture considered

PA: pipe assembly

The model allows to simulate the pumped flow rate from climatic and water consumption data. The inputs of the model are the irradiance on the plane of the PV modules $\operatorname{Irr}_{P V}$, the ambient temperature $T_{a}$ and the water consumption at the fountain $Q_{c}$. The model output is the pumped flow rate $Q_{p}$. The block diagram of the model is given on Fig. 2.

The model is used to simulate the operation of a real PVWPS installed in the rural village of Gogma in the centereastern Burkina Faso (GPS coordinates: 11.724586; - 0.572290). The system was set up in December 2017 by the company DargaTech, based in Ouagadougou, in collaboration with our research groups. In Gogma the inhabitants mostly work on agriculture for less than 1 \$ per day and houses neither have access to electricity nor to piped water. The PVWPS provides water to approximately 250 people each day for 4 types of domestic uses: drinking, cooking, body hygiene and laundry. Fig. 3 shows this PVWPS. There are $750 \mathrm{Wp}$ of PV modules, which corresponds to a total surface of $3.9 \mathrm{~m}^{2}$, the motor-pump is immersed at $30 \mathrm{~m}$ underground, the volume of the tank is $9.1 \mathrm{~m}^{3}$ and there are three taps at the fountain. The average daily volume collected by the users is $8.7 \mathrm{~m}^{3}$.

In Gogma, the inputs and the output of the model have been measured from January 2018 onward by using a data logger that we developed. Here we use measurements separated by a 1 minute time interval. The comparison between the measured pumped flow rate and the one simulated by the model for several periods of the year allowed to validate the model experimentally. Fig. 4 shows this comparison for the $22^{\text {nd }}$ of February 2018. On this figure, the interruptions in the pumped flow rate profile correspond to the moments at which the tank is full and show that Gogma's PVWPS is oversized. 


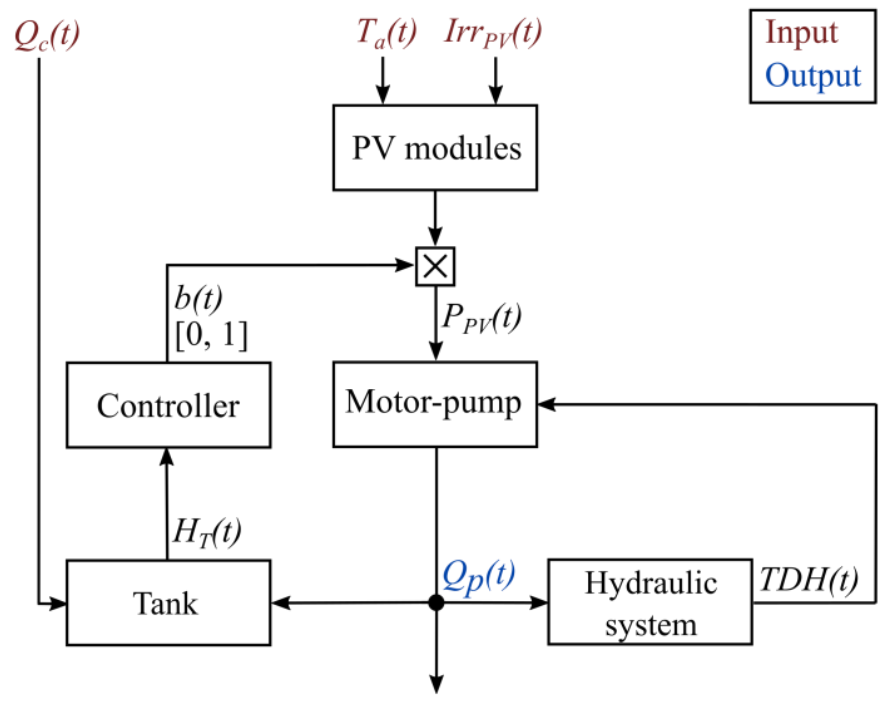

Fig. 2 Block diagram of the PVWPS model

$t$ : time, $P_{P V}$ : Input power to the motor-pump, $T D H$ : total dynamic head, $H_{T}$ : water level in the tank, $b$ : triggering signal from the controller

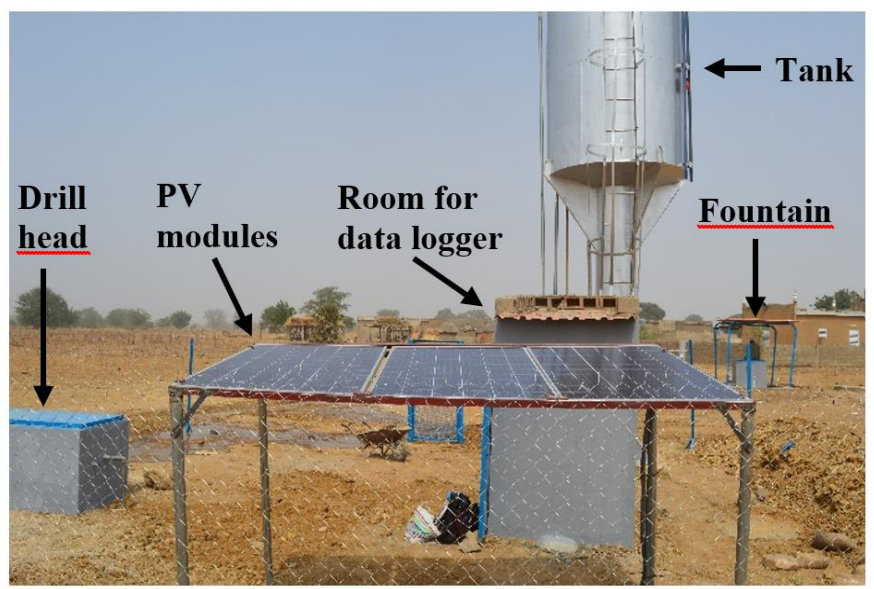

Fig. 3 Picture of the PVWPS of Gogma

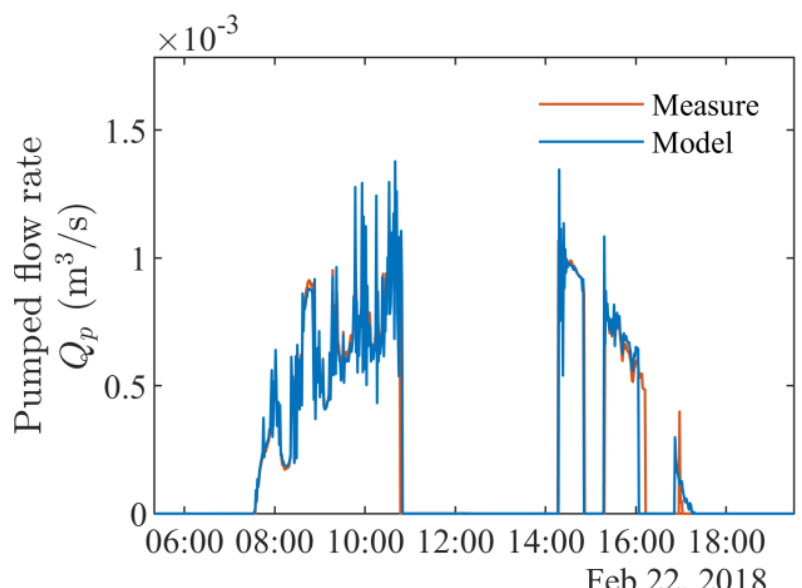

Fig. 4 Comparison between the measured and modelled pumped flow rate

\section{WATER CONSUMPTION PROFILE TEMPORAL RESOLUTION}

In order to observe the impact of a decreasing temporal resolution of the water consumption profile, we build several profiles from the measured dataset. To do so, we replace all the values of water consumption flow rate in a time interval $\mathrm{T}$ by the average of those values. This averaging corresponds to acquiring data from a water meter at a given time interval $\mathrm{T}$. Fig. 5 presents the water consumption profile measured by the data logger and the profiles obtained with some selected time intervals, for the $22^{\text {nd }}$ of February 2018. In total 15 time intervals, ranging from $1 \mathrm{~min}$ to 1 day have been considered for this study and for all of these intervals the total volume consumed during the day is the same.

\section{EFFECT OF THE TEMPORAL RESOLUTION ON MODEL ACCURACY}

The impact of the temporal resolution on the model accuracy is evaluated by computing the pumped flow rate from the PVWPS model for different temporal resolutions of the water consumption profile. Fig. 6 compares, for the $22^{\text {nd }}$ of February, the pumped flow rate measured by the data logger to the pumped flow rate computed by the model for a temporal resolution of the water consumption profile of 1 hour. The initial water level in the tank is equal to the one at the beginning of the $22^{\text {nd }}$ of February, $2.0 \mathrm{~m}$. Fig. 7 performs the same comparison as Fig. 6 but a temporal resolution of 1 day is considered. We observe that the larger the time interval used for the water consumption profile, the higher the mismatch between the measured and the modelled pumped flow rate.

To quantify the loss of accuracy, the root mean square error (RMSE) between the measured and simulated pumped flow rate is computed for each temporal resolution. This RMSE is normalized by the maximum measured pumped flow rate, which is equal to $1.2 \times 10^{-3} \mathrm{~m}^{3} / \mathrm{s}$ on the $22^{\text {nd }}$ of February. The results on the normalized RMSE for the $22^{\text {nd }}$ of February are presented on Fig. 8.

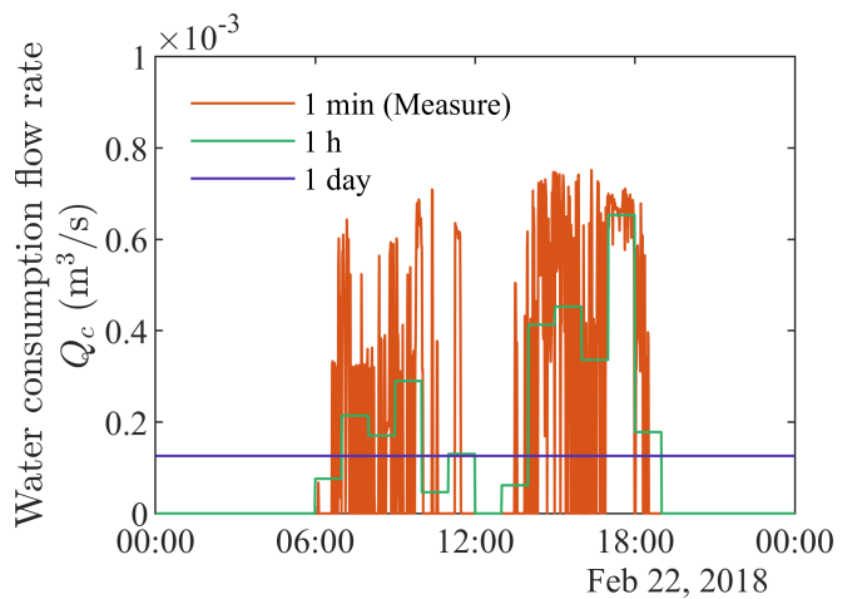

Fig. 5 Water consumption profiles obtained for various temporal resolutions 


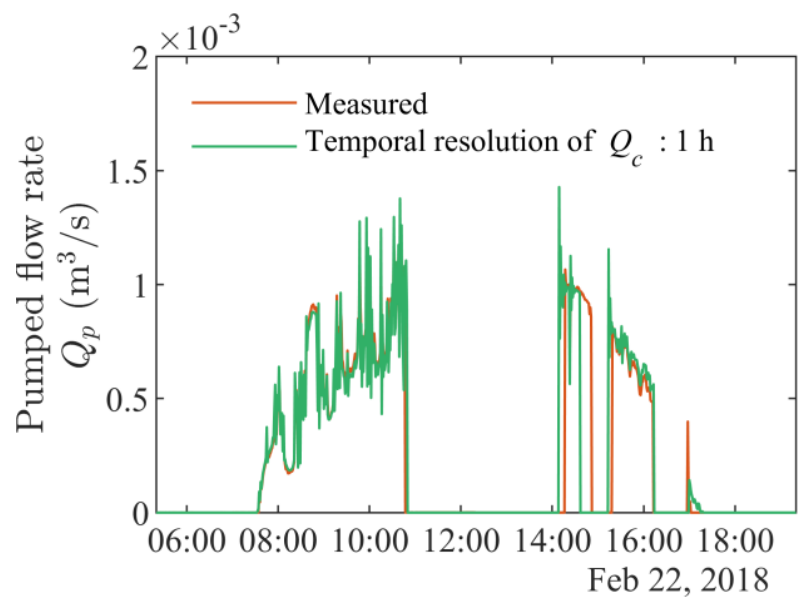

Fig. 6 Measured pumped flow rate and pumped flow rate simulated for a temporal resolution of the water consumption profile of 1 hour

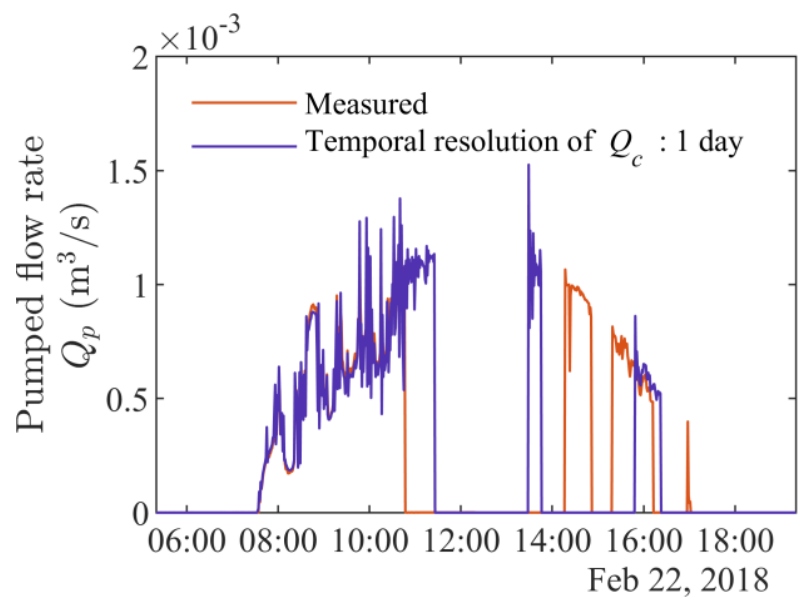

Fig. 7 Measured pumped flow rate and pumped flow rate simulated for a temporal resolution of the water consumption profile of 1 day

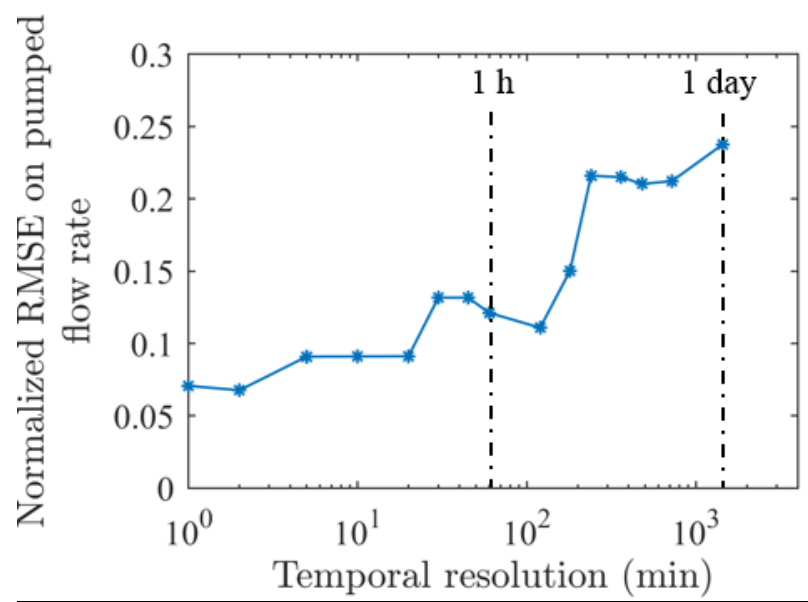

Fig. 8 RMSE on the pumped flow rate for various temporal resolutions Results for the data of the $22^{\text {nd }}$ of February

We observe that, for the $22^{\text {nd }}$ of February, the normalized RMSE is multiplied by 3 as the temporal resolution goes from 1 minute to 4 hours. Moreover, the first sharp increase of the RMSE take place for time intervals strictly larger than 20 minutes. The same study was performed for other days of the data set and trends similar to the one for the $22^{\text {nd }}$ of February were observed.

We also notice that, despite the fact that the temporal resolution strongly influences the simulated instantaneous pumped flow rate, it has a smaller impact on the simulated total volume pumped during the day. For instance, for the data of the $22^{\text {nd }}$ of February, the simulated total volume pumped during the day is comprised between $10 \mathrm{~m}^{3}$ and $13 \mathrm{~m}^{3}$ for all of the temporal resolutions.

\section{EFFECT OF THE TEMPORAL RESOLUTION ON SYSTEM SIZING}

We now study the effect of the temporal resolution of the water consumption profile on the PVWPS optimal conception. In this optimization problem, we search with the help of a differential evolution algorithm [19] for the values of the PV modules area $A_{P V}$ and of the tank volume $V_{T}$ that minimize the part of the capital cost that depends on the size of the PV modules and of the tank, CAPEX. The fixed part of the capital cost is not included in the objective function as it does not influence the result of the optimization. The CAPEX, expressed in $\mathrm{k} \$$, is given by:

$$
C A P E X=0.16 A_{P V}+0.61 V_{T}
$$

The coefficients have been obtained by using prices provided by companies located in Burkina Faso [20]. We have set the constraints that the water level in the tank must remain higher than zero and that the instantaneous pumped flow rate must remain lower than $1.3 \times 10^{-3} \mathrm{~m}^{3} / \mathrm{s}$. Indeed, we have noticed during pumping tests that were performed at Gogma's PVPWS that too high pumped flow rates produce a significant decrease of the water level in the borehole and may therefore cause the pump to run dry. It is important to notice that the PVWPS model is required to verify these two constraints. This is therefore at this stage that the temporal resolution of the water consumption profile has an influence. Indeed the temporal resolution of the water consumption profile impacts the evolution of the pumped flow rate and of the water level in the tank. During the optimization process, the model is run over three periods of $24 \mathrm{~h}$ and the model input data are the same for these three periods, equal to the data of the $22^{\text {nd }}$ of February 2018. Indeed, the results of the model for the following periods are identical to the results for the third one, which means that the system has reached a steady state at the third period. Fig. 9 presents, for the data of the $22^{\text {nd }}$ of February, the values taken by the optimization's variables and the optimum CAPEX obtained for different temporal resolutions of the water consumption profile.

It appears on Fig. 9 that the first significant changes in the optimal PV panels area take place for time intervals strictly larger than 45 minutes. However, the first significant changes in the tank volume and in the cost function take place for time intervals strictly larger than 4 hours. This difference may be due to the fact that the weight of the tank volume in the cost function is higher than the weight of the PV panels area. When we performed the same study for other days of the dataset, it appeared that the results follow the same trend as the ones of the $22^{\text {nd }}$ of February. 


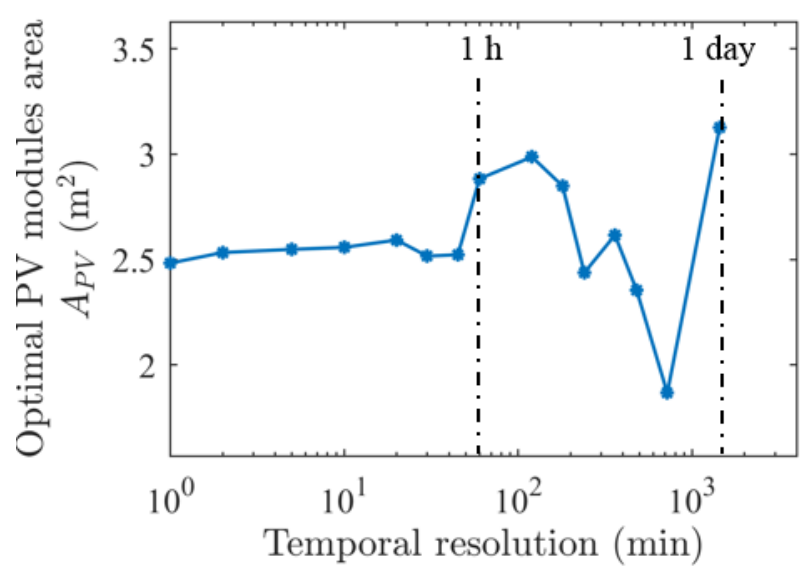

(a)

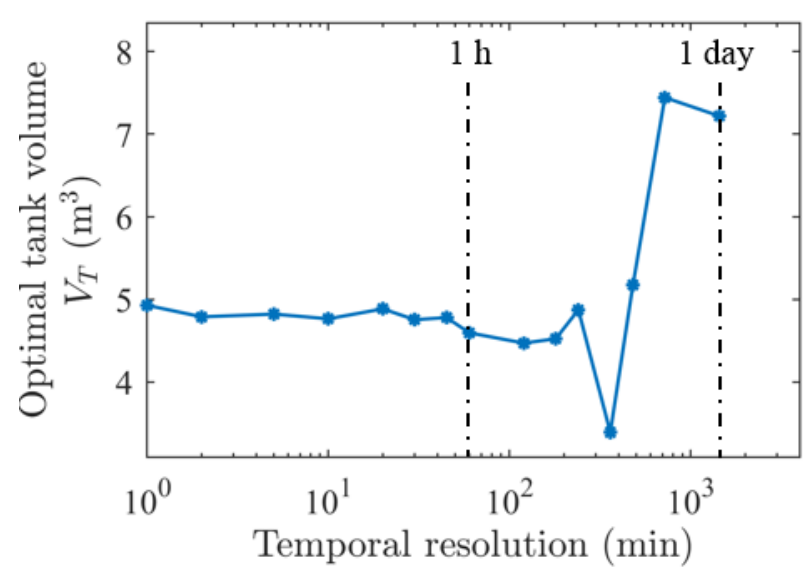

(b)

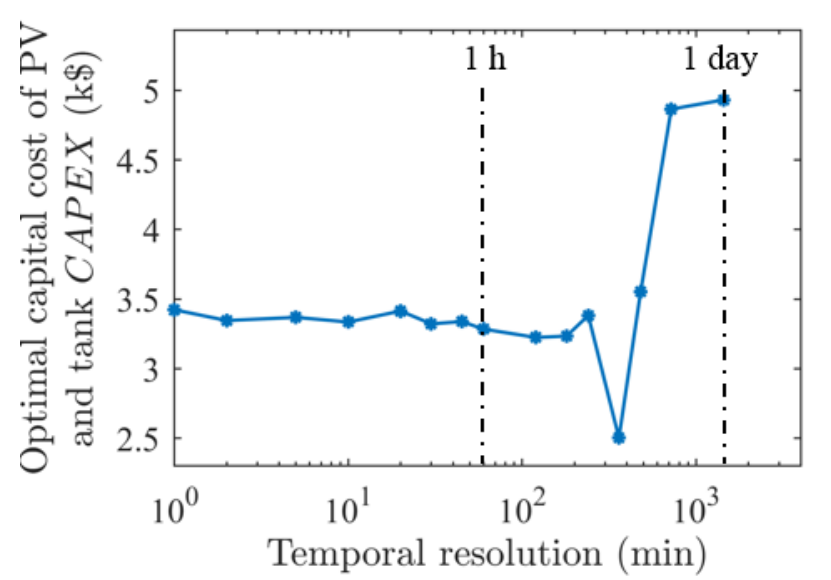

(c)

Fig. 9 Effect of the temporal resolution on PVWPS optimal sizing Results on PV modules area (a), tank volume (b) and CAPEX (c) Results for the data of the $22^{\text {nd }}$ of February

\section{CONCLUSION}

The main contribution of this article is to provide a first estimation of the water consumption profile temporal resolutions required for accurately modelling and sizing PVWPS for domestic consumption in remote villages. It appears that, for the day presented in this article, time intervals strictly larger than 20 minutes significantly change the model accuracy and that time intervals strictly larger than 4 hours have a strong impact on the optimal system sizing. The results presented here and simulations performed for other days of our dataset highlight that the temporal resolution strongly influences the model accuracy and the optimal system sizing. This suggests that current sizing methods, which are often based on the forecasted daily water consumption and therefore use a time interval of 1 day, may lead to badly sized PVWPS. This highlights the importance of developing methods that allow to forecast the water consumption profile with a time step smaller than one day. The methodology presented in this article could also be used to study the effects of the water consumption profile temporal resolution for other types of pumping systems with tanks, such as wind powered pumping systems or piped water pumping systems. In the future, we will perform the simulations by using larger datasets, such as periods of one week instead of periods of one day. We will also study the influence of the temporal resolution of the irradiance profile and of the ambient temperature profile on PVWPS modelling and optimal conception.

\section{REFERENCES}

[1] United Nations, "The Millennium Development Goals Report," 2015.

[2] G. Howard and J. Bartram, "Domestic water quantity, service level, and health," World Health Organization, 2003.

[3] J. Bartram and S. Cairncross, "Hygiene, Sanitation, and Water: Forgotten Foundations of Health," PLoS Med., vol. 7, no. 11, p. e1000367, Nov. 2010.

[4] B. Singh, A. K. Mishra, and R. Kumar, "Solar Powered Water Pumping System Employing Switched Reluctance Motor Drive," IEEE Trans. Ind. Appl., vol. 52, no. 5, pp. 3949-3957, Sep. 2016.

[5] M. I. Chergui and M. O. Benaissa, "Strategy photovoltaic pumping system in scattered area," International Conference on Renewable Energy Research and Applications (ICRERA), Palermo, Italy, pp. 283286, Nov. 2015

[6] J. V. Mapurunga Caracas, G. De Carvalho Farias, L. F. Moreira Teixeira, and L. A. De Souza Ribeiro, "Implementation of a HighEfficiency, High-Lifetime, and Low-Cost Converter for an Autonomous Photovoltaic Water Pumping System," IEEE Trans. Ind. Appl., vol. 50, no. 1, pp. 631-641, Jan. 2014.

[7] S. K. Jha, "Application of solar photovoltaic system in Oman-Overview of technology, opportunities and challenges,” Int. J. Renew. Energy Res. (IJRER), vol. 3, no. 2, pp. 331-340, 2013.

[8] L. Quéval, A. Coty, L. Vido, R. Gottkehaskamp, and B. Multon, "A Switched Reluctance Motor Drive using Photovoltaic Transistors: Principle, Prototype, Experimental and Numerical Results," International Conference on Renewable Energy Research and Applications (ICRERA), Palermo, Italy, pp. 369-374, Nov. 2015.

[9] I. Ouachani, A. Rabhi, B. Tidhaf, S. Zouggar, and A. Elhajjaji, "Optimization and control for a photovoltaic pumping system," International Conference on Renewable Energy Research and Applications (ICRERA), Madrid, Spain, pp. 734-739, Oct. 2013.

[10] M. Bahloul, L. Chrifi-Alaoui, M. Souissi, M. Chabaane, and S. Drid, "Effective Fuzzy Logic Control of a Stand-alone Photovoltaic Pumping System," Int. J. Renew. Energy Res. (IJRER), vol. 5, no. 3, pp. 677-685, 2015.

[11] S. Krim, S. Gdaim, A. Mtibaa, and M. F. Mimouni, "FPGA Contribution in Photovoltaic Pumping Systems: Models of MPPT and DTC-SVM Algorithms,” Int. J. Renew. Energy Res. (IJRER), vol. 6, no. 3, 2016.

[12] V. B. Koreboina, B. L. Narasimharaju, and D. M. Vinod Kumar, "Performance Evaluation of Switched Reluctance Motor PWM Control 
in PV-fed Water Pump System," Int. J. Renew. Energy Res. (IJRER), vol. 6, no. 3, 2016.

[13] O. M. Akeyo, V. Rallabandi, and D. M. Ionel, "Multi-MW solar PV pumping system with capacity modulation and battery voltage support," International Conference on Renewable Energy Research and Applications (ICRERA), San Diego, United States, pp. 423-428, Nov. 2017.

[14] I. Yahyaoui, M. Chaabene, and F. Tadeo, "An Algorithm for Sizing Photovoltaic Pumping Systems for Tomatoes Irrigation,” International Conference on Renewable Energy Research and Applications (ICRERA), Madrid, Spain, Oct. 2013.

[15] J. Sodiki, "Solar-powered groundwater pumping systems for Nigerian water sheds," Int. J. Renew. Energy Res. (IJRER), vol. 4, no. 2, pp. 294 304, 2014.

[16] G. Notton, M. Muselli, P. Poggi, and A. Louche, "Autonomous photovoltaic systems: Influences of some parameters on the sizing:
Simulation timestep, input and output power profile," Renewable Energy, vol.7, no. 4, pp 353-369, 1996.

[17] E. J. Hoevenaars and C. A. Crawford, "Implications of temporal resolution for modeling renewables-based power systems," Renew. Energy, vol. 41, pp. 285-293, May 2012.

[18] S. Meunier, M. Heinrich, J. A. Cherni, L. Queval, P. Dessante, L. Vido, A. Darga, B. Multon and C. Marchand, "Modélisation et validation expérimentale d'un système de pompage photovoltaïque dans une communauté rurale isolée du Burkina Faso," Symposium de Génie Electrique (SGE), Nancy, France, Jul. 2018.

[19] K. Price, R. M. Storn, and J. A. Lampinen, Differential Evolution: A Practical Approach to Global Optimization (Natural Computing Series). Secaucus, NJ, USA: Springer-Verlag New York, Inc., 2005.

[20] E. André de La Fresnaye, "A financial and technical assessment of solar versus hand water pumping for off-grid area - the case of Burkina Faso," Imperial College London, MSc Thesis, 2018. 